\title{
Glandular Liposculpture in the Treatment of Gynecomastia
}

\author{
S. S. Shirol ${ }^{1,2}$
}

Received: 30 March 2018/Accepted: 3 April 2018/Published online: 11 April 2018

(C) Springer Science+Business Media, LLC, part of Springer Nature and International Society of Aesthetic Plastic Surgery 2018

Level of Evidence $V$ This journal requires that authors assign a level of evidence to each article. For a full description of these Evidence-Based Medicine ratings, please refer to the Table of Contents or the online Instructions to Authors www.springer.com/00266.

\section{Dear Sir,}

We read with interest, the article titled "Evaluation of glandular liposculpture as a single treatment for grades I and II Gynecomastia" [1]. We must congratulate the authors for their innovative glandular liposculpture treatment of gynecomastia. We do agree with the view that gynecomastia has a tremendous psychological impact on the patients ranging from anxiety, depression, to inferiority complexes, and our experience also supports this [2]. The patients approach us with either aesthetic or psychological concerns. Planning both the incisions away from the breast aesthetic unit and NAC avoids scarring of the NAC, chances of NAC retraction and hypo-pigmentation of the areola. The assessment of results by using the BEQ by plastic surgeons who have least trained for at least 10 years in reconstructive surgeries and are blinded makes the assessment much more objective and avoids the possibility of bias. The idea of using three-dimensional photography for better evaluation seems innovative and may be a gamechanger for evaluation in the future.

\section{S. S. Shirol}

ssshirol@yahoo.co.uk

1 Department of Plastic Surgery, Karnataka Institute of Medical Sciences, Hubli, Karnataka, India

2 Sampige Plastic Surgery Centre, 1st Floor, Divate Complex, Opposite Vasan Eye Care, Club Road, Near Court Circle, Hubli, Karnataka 580028, India
However, the Mercedes Benz tip and barbed edges of the lipodisruptive cannulas are quite traumatic to the skin, vascular, nervous and glandular tissues increasing the chances of hematoma [3]. Unlike the authors, we use customized pressure garments continuously for 10 days and then on/off for 3 months; our patients resume routine work from the next day of surgery and avoid heavy weight lifting and the gym for 3 weeks postoperatively. We used general anesthesia in all patients undergoing gynecomastia surgery [2] unlike the authors until the end of 2016, but we have been using tumescent anesthesia since 2017 without any sedation; this has reduced the cost of surgery, hospital stay and time off from work significantly.

\section{Compliance with Ethical Standards}

Conflict of interest The author declares that he has no conflict of interest.

\section{References}

1. Abdelrahman I, Steinvall I, Mossaad B, Sjoberg F, Elmasry M (2018) Evaluation of glandular liposculpture as a single treatment for grades I and II gynaecomastia. Aesthet Plast Surg 16:1-9

2. Shirol SS (2016) Orange peel excision of gland: a novel surgical technique for treatment of gynecomastia. Ann Plast Surg 77(6):615-619

3. Pelosi MA (2015) Breast liposuction. In: Mugea - Clinica Medestet TT, Shiffman MA (eds) Aesthetic surgery of the breast 2015. Springer, Berlin, pp 883-894 